\title{
Acid-Base Properties of Aqueous Illite Surfaces
}

\author{
Qing Du, $* \dagger$ Zhongxi Sun, $*$ Willis Forsling, ${ }^{*}, 1$ and Hongxiao Tang $\dagger$ \\ * Division of Inorganic Chemistry, Luleå University of Technology, S-971 87 Luleå, Sweden; and \\ $\dagger$ Research Center for Eco-Environmental Sciences, Academia Sinica, 100085 Beijing, China
}

Received August 2, 1996; accepted October 31, 1996

\begin{abstract}
In this paper, the acid-base properties of illite/water suspensions are examined using the constant capacitance surface complexation model. On the basis of results of potentiometric titrations and solubility experiments, we conclude that the proton reactions in the supernatants of illite suspensions can be successfully represented by proton reactions of $\mathrm{Al}\left(\mathrm{H}_{2} \mathrm{O}\right)_{6}^{3+}$ and $\mathrm{Si}(\mathrm{OH})_{4}$ in water solutions. For illustrating the acidic characteristics of aqueous illite surfaces, two surface protonation models are proposed: (1) one site- one $\mathrm{p} K_{\mathrm{a}}$ model, $\equiv \mathrm{SOH} \rightleftarrows \equiv \mathrm{SO}^{-}+\mathrm{H}^{+}, \mathrm{p} K_{\mathrm{a}}^{\text {int }}=4.12-4.23$; (2) two sites- two $\mathrm{p} K_{\mathrm{a}} \mathrm{S}$ model, $\equiv \mathrm{S}_{1} \mathrm{OH} \rightleftarrows \equiv \mathrm{S}_{1} \mathrm{O}^{-}+\mathrm{H}^{+}, \mathrm{p} K_{\mathrm{a}_{1}}^{\mathrm{int}}$ $=4.17-4.44$, and $\equiv \mathrm{S}_{\mathrm{II}} \mathrm{OH} \rightleftharpoons \equiv \mathrm{S}_{\| I} \mathrm{O}^{-}+\mathrm{H}^{+}, \mathrm{pK}_{\mathrm{a}_{\| 1}}^{\mathrm{int}}=6.35-7.74$. Evaluation of these two models indicates that both of them can give good descriptions of the experimental data of systems with different illite concentrations and ionic strengths and that the one site- one $\mathrm{p} K_{\mathrm{a}}$ model can be considered as a simplification of the two sites- two $\mathrm{p} K_{\mathrm{a}} s$ model. Since both models assume only deprotonation reactions at the illite surfaces, they suggest that the surface behavior of the illite is similar to that of amorphous $\mathrm{SiO}_{2}$. Model assumptions, experimental procedures, and evaluative criteria are detailed in the paper. @ 1997 Academic Press
\end{abstract}

Key Words: illite; acid- base properties; potentiometric titrations; constant capacitance model.

\section{INTRODUCTION}

Reactions at natural particle surfaces play important roles in determining the distributions and destinations of contaminants in aquatic environments, and many studies have been done to interpret their surface reactive characteristics, specifically surface charge $(1,2)$ and surface complexation (37 ) properties. Up to now, most models proposed to illustrate the surface reaction mechanisms have, for the sake of theoretical simplicity, considered natural particles as unanalyzed wholes. However, natural minerals are in fact quite complex, being composed of clay minerals, metal hydroxides, and humic materials. Therefore, traditional holistic surface reaction models are limited in representing many of the surface behaviors in real-world natural systems, which in turn limits their practical explanatory and predictive value.

\footnotetext{
${ }^{1}$ To whom correspondence should be addressed.
}

A first step in refining traditional holistic models is to isolate and analyze the surface reaction mechanisms of different components in natural particles. Of particular interest are clays, since they are the dominant components in natural minerals. As to what has already been done in this area, Schindler's research group $(8,9)$ has modified and extended the constant capacitance model, which has been successfully used to describe the amphoteric acid-base behaviors of inorganic surface groups on oxide (10-14) and sulfide minerals (15-17), to interpret the surface acid-base properties of the clay minerals kaolinite (a 1:1 layer-type clay mineral) and montmorillonite (a 2:1 layer-type clay mineral). For the study of kaolinite (8), in addition to the amphoteric surface hydroxyl group, $\equiv \mathrm{SOH}$, they postulate a second surface functional group, $\equiv \mathrm{XH}$, which is weakly acidic and can undergo ion exchange with cations from the background electrolyte. For the study of montmorillonite (9), besides $\equiv \mathrm{SOH}$ and $\equiv \mathrm{XH}$, another surface hydroxyl group $\equiv \mathrm{TOH}$, which undergoes one deprotonation reaction, is incorporated to evaluate the surface acid-base behaviors. Wieland and Stumm (18-20) have studied the dissolution kinetics of kaolinite using the constant capacitance model and have given some suggestions about the possible reactive sites at the kaolinite surface. They explain the $\mathrm{pH}$-dependent surface charge as due primarily to the protonation of the hydroxyl groups at the basal gibbsite and the edge surface. Motta and Miranda (21) have also applied the constant capacitance model to study the behaviors of kaolinite, illite and montmorillonite and derive surface acidic constants of each clay mineral from their experimental data.

Although illite is an important clay mineral occupying half or more of the clay minerals in the earth's crust (22), until now no intensive study of the surface characteristics and reaction mechanisms at the illite/water interface has been made. To fill this gap, we have conducted a study to investigate the acid-base properties of illite/water suspensions. In the study, the surface reaction mechanisms were interpreted using the constant capacitance surface complexation model; the proton reactions both at the illite surfaces and in the supernatants were modeled using parameters derived from experimental data by a nonlinear least squares optimization program, FITEQL (23). 


\section{THE CHEMICAL EQUILIBRIA OF THE CONSTANT CAPACITANCE MODEL}

The constant capacitance model developed by Schindler and Stumm $(10,11,24,25)$ is based on the following assumptions $(26,27)$ :

(1) In a solid/water suspension, the amphoteric surface hydroxyl groups form ionized surface sites as shown in Eqs. [1] and [2].

$$
\begin{aligned}
\equiv \mathrm{SOH}_{2}^{+} & \equiv \mathrm{SOH}+\mathrm{H}^{+}, K_{\mathrm{a} 1} \\
& =\mathrm{SOH} \rightleftarrows \mathrm{SO}^{-}+\mathrm{H}^{+}, K_{\mathrm{a} 2}
\end{aligned}
$$

These two reactions are described by the two intrinsic equilibrium constants,

$$
K_{\mathrm{a} 1}^{\mathrm{int}}=\frac{[\equiv \mathrm{SOH}]\left[\mathrm{H}^{+}\right]}{\left[\equiv \mathrm{SOH}_{2}^{+}\right]} \exp \left(-\mathrm{F} \Psi_{0} / R T\right)
$$

and

$$
K_{\mathrm{a} 2}^{\mathrm{int}}=\frac{\left[\equiv \mathrm{SO}^{-}\right]\left[\mathrm{H}^{+}\right]}{[\equiv \mathrm{SOH}]} \exp \left(-\mathrm{F} \Psi_{0} / R T\right),
$$

where $F$ is the Faraday constant $\left(\mathrm{C} \mathrm{mol}^{-1}\right), \Psi_{0}$ the surface potential (V), $R$ the molar gas constant $\left(\mathrm{J} \mathrm{mol}^{-1} \mathrm{~K}^{-1}\right)$, and $T$ the absolute temperature $(\mathrm{K})$. The values of the constants, however, are valid only for a particular ionic strength (28).

(2) Only one plane in the interfacial region is considered. All surface complexes are inner-sphere complexes. The background electrolyte ions, e.g., $\mathrm{Na}^{+}, \mathrm{K}^{+}, \mathrm{Cl}^{-}$, and $\mathrm{NO}_{3}^{-}$, are assumed to be inert with respect to the surface.

(3) The surface charge-potential relationship is expressed as

$$
\sigma_{0}=\sigma_{\mathrm{H}}+\sigma_{\mathrm{is}}=C \Psi_{0},
$$

where $C$ is the specific capacitance of the mineral/water interface. The surface charge $\sigma_{0}$ equals the net proton charge $\left(\sigma_{\mathrm{H}}\right)$ plus the charge resulting from the formation of the inner-sphere surface complexes $\left(\sigma_{\text {is }}\right)$.

For fitting the acid-base titration data of a mineral suspension in a simple 1:1 electrolyte, the model has three adjustable parameters $\left(K_{\mathrm{a} 1}^{\mathrm{int}}, K_{\mathrm{a} 2}^{\mathrm{int}}\right.$, and C) for each ionic strength.

\section{MATERIALS AND METHODS}

\section{Materials}

The sample of illite used in our experiments was obtained from Hebei Province, China. It was prepared by being ground and passed through a sieve of 240 mesh $(63 \mu \mathrm{m})$. Two weeks prior to the experiments, a stock suspension of $10 \mathrm{~g} /$ liter illite was made and stored in a refrigerator. The element composition of the illite was measured by an X-ray fluorescence spectrograph, the results of which are given in Table 1. X-ray diffraction analysis showed that the major components in the illite were $90 \%$ pure illite, $5 \%$ chlorite, and $5 \%$ quartz, and that the average value of the distance between layers in the crystal structure was $10.05 \AA$. The specific surface area, determined by the $\mathrm{N}_{2}$ /BET method, was $22.3 \mathrm{~m}^{2} \mathrm{~g}^{-1}$. The particles of illite appeared as platelike crystals arranged in stacks under the scanning electron microscope (SEM) (Fig. 1).

Diluted $\mathrm{HNO}_{3}$ solution was standardized against tris (hydroxymethyl) aminomethane (THAM). $\mathrm{NaOH}$ solution was prepared from BDH concentrated solutions and standardized using an acid of known concentration.

\section{Apparatus}

The potentiometric titrations were performed using an automatic system for precise emf titrations constructed by Ginstrup (29). The cell arrangement, similar to that described by Forsling et al. (30), was immersed in an oil thermostat at $25.0 \pm 0.5^{\circ} \mathrm{C}$. For the $\mathrm{H}^{+}$measurements, a glass electrode (Ingold type 201-NS) with a double junction $\mathrm{Ag} / \mathrm{AgCl}$ reference electrode (Orion 90-02) was used.

The element concentrations in the supernatants of the solubility experiments were analyzed by an ARL 3580 inductively coupled plasma-atomic emission spectrometer (ICPAES ). The zeta potential of the illite suspension was measured by a Zeta Plus zeta potential analyzer made by Brookhaven Instruments Corporation. The carbonates in the illite were analyzed by the Brüel \& Kjær Gas Analyzer type 1301, which photoacoustically measures the absorption of infrared light by gas samples.

\section{Solubility of the Illite at Different $\mathrm{pH}$ Values}

This experiment was carried out in batch systems using a group of $50 \mathrm{ml}$ bottles. Each sample contained $3 \mathrm{ml}$ of 10 $\mathrm{g} /$ liter illite and an increment of $0.08953 \mathrm{M} \mathrm{HNO}_{3}$ or $0.09330 M \mathrm{NaOH}$ to adjust the $\mathrm{pH}$ value of the suspension between 2 and 10. Distilled water was added to bring the total volume to $30 \mathrm{~mL}$ with an illite concentration of $1 \mathrm{~g} /$ liter. No background electrolyte was used in this experiment. The samples were magnetically stirred at room temperature for $24 \mathrm{~h}$. Then, the suspensions were measured for $\mathrm{pH}$, centrifuged at $10,000 \mathrm{rpm}, 15^{\circ} \mathrm{C}$, for $20 \mathrm{~min}$. The supernatants were analyzed for $\mathrm{Ca}, \mathrm{Fe}, \mathrm{K}, \mathrm{Mg}, \mathrm{Na}, \mathrm{Si}, \mathrm{Al}$, and $\mathrm{Cu}$ by ICP-AES.

We then repeated the procedure using a $5 \mathrm{~g} /$ liter illite concentration.

\section{Potentiometric Titrations of Different Illite Suspensions}

A backtitration procedure, by which we first acidified the suspension to a $\mathrm{pH}$ of approximately 3 and then titrated with hydroxide to an alkaline condition, was used.

For each titration, a certain amount of $10 \mathrm{~g} /$ liter illite 
TABLE 1

Element Composition of the Illite

\begin{tabular}{lllllllll}
\hline Element & $\mathrm{Mg}$ & $\mathrm{Na}$ & $\mathrm{Fe}$ & $\mathrm{Ti}$ & $\mathrm{Ca}$ & $\mathrm{K}$ & $\mathrm{Si}$ & $\mathrm{Al}$ \\
Content $(\%)$ & 1.39 & 0.40 & 2.01 & 0.18 & 0.54 & 3.41 & 32.61 & 8.09 \\
Element & $\mathrm{Zn}$ & $\mathrm{Cu}$ & $\mathrm{Ni}$ & $\mathrm{Mn}$ & $\mathrm{Cr}$ & $\mathrm{Ba}$ & $\mathrm{Pb}$ & $\mathrm{S}$ \\
Content $(\mathrm{ppm})$ & 101 & 10 & 5 & 594 & 20 & 510 & 64 & 156 \\
Element & $\mathrm{P}$ & $\mathrm{Zr}$ & $\mathrm{Sr}$ & $\mathrm{As}$ & & & & \\
Content $(\mathrm{ppm})$ & 190 & 268 & 30 & 8 & & & \\
\hline
\end{tabular}

stock suspension was added to a $100 \mathrm{ml}$ flask. $1 M \mathrm{NaNO}_{3}$ was used to stabilize the system at a fixed ionic strength. Distilled water was added to bring the total initial volume of the suspension to $50 \mathrm{ml} . \mathrm{N}_{2}$ was bubbled successively through $10 \% \mathrm{NaOH}, 10 \% \mathrm{H}_{2} \mathrm{SO}_{4}$, distilled water, and 0.1 $M \mathrm{NaNO}_{3}$, and then into the suspension to exclude $\mathrm{CO}_{2}$ until the electrode potential was stable. Afterwards, $0.08953 M$ $\mathrm{HNO}_{3}$ in increments of $0.1 \mathrm{ml}$ was added gradually. When the $\mathrm{pH}$ of the system dropped below 3, $0.02220 \mathrm{M} \mathrm{NaOH}$ in $0.1 \mathrm{ml}$ increments was used to backtitrate the suspension up to a $\mathrm{pH}$ of approximately 11 . During the titration period, $\mathrm{N}_{2}$ was bubbled to exclude $\mathrm{CO}_{2}$ and the mixture was stirred magnetically, the temperature being held constant at $25 \pm$ $0.5^{\circ} \mathrm{C}$. The equilibrium criterion for each addition of the titrant was that the drift in the measured potential was lower than $1 \mathrm{mV} / \mathrm{h}$. The equilibrium concentration of $\mathrm{H}^{+}$was calculated from the output of the glass electrode (emf) according to the Nernst equation

$$
E=E^{0}+59.157 \log \left[\mathrm{H}^{+}\right]
$$

where $E^{0}$ is a constant determined in each titration by an in-situ Gran plot method, which is described in detail in the next section.

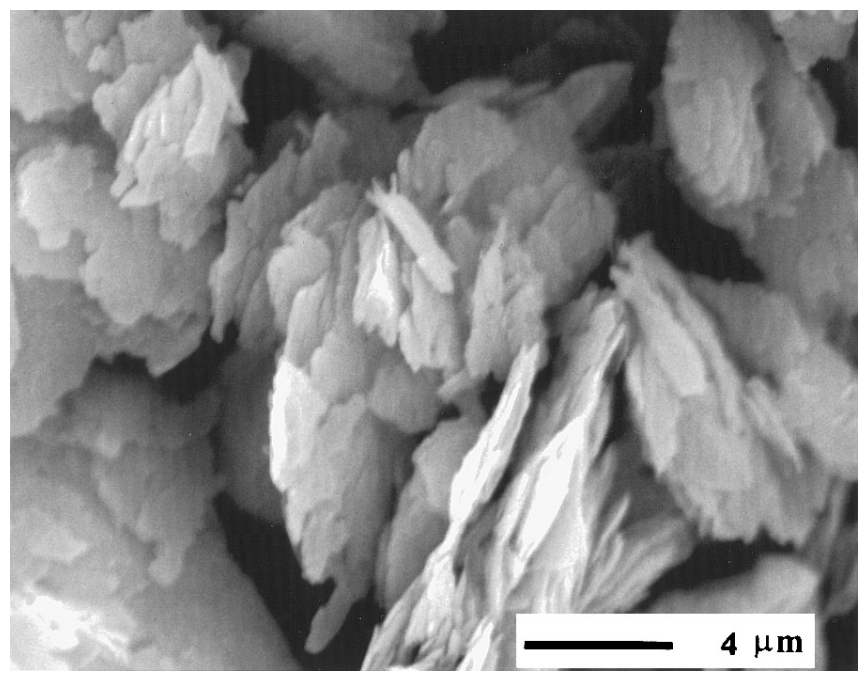

FIG. 1. Scanning electron microscope image of the studied illite $(<63$ $\mu \mathrm{m})$ showing plate-like crystals arranged in stacks. Scale bar $=4 \mu \mathrm{m}$.
Regarding the blank system for each sample, we used the supernatant of the corresponding sample system as the titration blank. The procedure for obtaining the supernatant was as follows. An illite suspension with the same composition as the one used in the corresponding sample titration was prepared. $\mathrm{N}_{2}$ was bubbled into the system until the electrode potential was stable. The suspension was centrifuged at $20,000 \mathrm{rpm}, 10^{\circ} \mathrm{C}$, for $30 \mathrm{~min}$. The supernatant thus obtained was bubbled with $\mathrm{N}_{2}$ again until the electrode potential was stable. Then this solution was titrated according to the backtitration procedure described above. The controlling condition during the titration was the same as that for the sample titration.

Three illite suspensions $\left(5 \mathrm{~g} /\right.$ liter illite in $0.1 M \mathrm{NaNO}_{3}$, $5 \mathrm{~g} /$ liter illite in $0.5 \mathrm{MNaNO}_{3}$, and $1 \mathrm{~g} /$ liter illite in $0.1 \mathrm{M}$ $\mathrm{NaNO}_{3}$ ) and their corresponding supernatant blank systems were titrated using this backtitration procedure.

\section{Zeta Potential Measurements}

To prepare the samples for zeta potential measurements, $0.5 \mathrm{ml}$ of $10 \mathrm{~g} /$ liter illite stock suspension and $0.05 \mathrm{ml}$ of $1 \mathrm{M} \mathrm{NaNO}_{3}$ was added to each of a group of $100 \mathrm{ml}$ plastic bottles. Increments of $0.1 M \mathrm{HNO}_{3}$ or $0.1 M \mathrm{NaOH}$ were used to adjust the $\mathrm{pH}$ of each sample to a value within the range 2-10. Distilled water was added to bring the total volume of each sample to $50 \mathrm{ml}$ with an illite concentration of $0.1 \mathrm{~g} /$ liter and an ionic strength of $0.001 \mathrm{MNaNO}_{3}$. The samples were shaken for $3 \mathrm{~h}$ and left overnight at $25 \pm$ $0.5^{\circ} \mathrm{C}$. The zeta potential of each sample was then measured by a zeta potential analyzer.

\section{Analysis of Carbonates in the Illite}

The Gas Analyzer Type 1301 was used to analyze the carbonates in each sample by measuring the amount of $\mathrm{CO}_{2}$ obtained after an addition of excess acid.

Before measuring the samples, the analyzer was first calibrated using pure $\mathrm{N}_{2}$ in order to compensate for the background signal in the chamber. Then, the analyzer was calibrated for $\mathrm{CO}_{2}$ measurement using a reference spectrum from a reference data disk supplied by the company. After the calibration of the instrument, each sample was analyzed using the procedure below.

A $50 \mathrm{ml}$ suspension with an exact amount of analyzed 

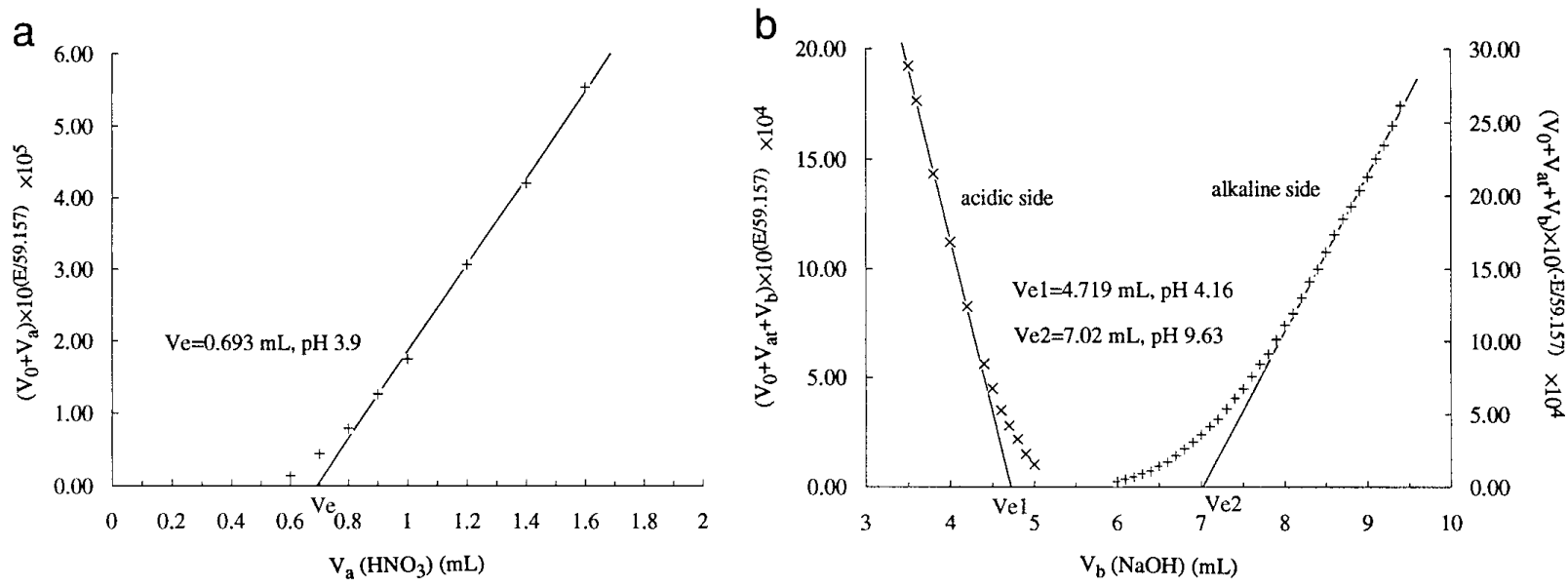

FIG. 2. Gran plots of a titration system with $5 \mathrm{~g} /$ liter illite in $0.1 M \mathrm{NaNO}_{3}$. a. Acid titration. b. Hydroxide titration.

solid was made and then purged by $\mathrm{N}_{2}$ for roughly $6 \mathrm{~h}$. Afterwards, the background $\mathrm{CO}_{2}$ concentration was measured at 4 scans, the sampling interval being $1 \mathrm{~min}$. Then the nitrogen outlet was closed and an excess amount of acid was added. The concentration of $\mathrm{CO}_{2}$ produced by the solid was recorded. After approximately $3 \mathrm{~h}$, the reaction equilibrium was reached.

Using the above method, we measured two standard samples with different amounts of calcite $\left(\mathrm{CaCO}_{3}\right)$ in $50 \mathrm{ml}$ distilled water to make a calibration curve $\left(\mathrm{CO}_{2}\right.$ concentration vs amount of calcite). Then the carbonates in $0.25 \mathrm{~g}$ illite, which was suspended in $50 \mathrm{ml}$ of a $0.1 \mathrm{M} \mathrm{NaNO}_{3}$ solution, were analyzed. The result is given as the corresponding amount of calcite.

\section{DATA TREATMENT}

\section{In-Situ Gran Plot Method}

Gran plots (31) are commonly used to determine the equivalence points of potentiometric titrations in solutions. For the titration of solid/water systems, some researchers have used a Gran titration $(2,9,32)$ which is carried out separately in the same ionic media as that in the suspension titration to determine the standard electrode potential $E^{0}$. In our work, we used an in-situ Gran plot method (15) to ascertain the volume of titrant added at the equivalence point $\left(V_{0}\right)$ and to calculate the standard electrode potential $\left(E^{0}\right)$ for each titration system.

For each studied system, Gran plots for the acid titration and the following hydroxide titration were made from the experimental data, and the $V_{\mathrm{e}}$ value was determined by linear regression in the corresponding Gran plot (as shown in Figs. $2 \mathrm{a}$ and $2 \mathrm{~b}$ ). The $V_{\mathrm{e}}$ values obtained from the Gran plots in the acidic region (i.e., $V_{\mathrm{e}}$ in Fig. $2 \mathrm{a}$ and $V_{\mathrm{e} 1}$ in Fig. $2 \mathrm{~b}$ ) were then used to calculate the $E^{0}$ value of the corresponding titration. For each titration system, two very close $E^{0}$ values $\left(\Delta E^{0}<2.0 \mathrm{mV}\right.$ ) were obtained from the acid titration and the following hydroxide titration, and the mean value of the two was used to calibrate the output of the glass electrode emf (potential $E$ in $\mathrm{mV}$ ) into the $\mathrm{pH}$ value in terms of $\mathrm{H}^{+}$ concentration.

\section{Calibration of the Zero Titration Point (ZTP)}

We took the $V_{\mathrm{e} 1}$ value obtained from the Gran plot of the hydroxide titration as the zero titration point (ZPT) for the following reasons. During the hydroxide titration, the added $\mathrm{NaOH}$ first reacted with the excess $\mathrm{HNO}_{3}$ added from the acid titration. After that, the added $\mathrm{OH}^{-}$began to react with the solid surface and the remainder contributed to the $\mathrm{pH}$ value of the system. (This can be clearly seen from the Gran plot in Fig. 2b, which shows that before the $V_{\mathrm{e} 1}$ point, there were no reactions in the system, except for acid-base neutralization.) Therefore, for each titration point, the concentration of the total protons added to the system was calculated by

\section{TOTH}

$$
=-\left(V_{\mathrm{b}}-V_{\mathrm{e} 1}\right) \mathrm{C}_{\mathrm{b}} /\left(V_{0}+V_{\mathrm{at}}+V_{\mathrm{b}}\right),(\text { mol/liter })
$$

where $V_{\text {at }}$ is the total volume of $\mathrm{HNO}_{3}$ added in the acid titration, $V_{\mathrm{b}}$ is the volume of $\mathrm{NaOH}$ added in the hydroxide backtitration, $V_{0}$ is the initial volume of the suspension, and $C_{\mathrm{b}}$ is the concentration of $\mathrm{NaOH}$. The hydroxide titration data after the calibration of ZTP were used in the FITEQL program to calculate the surface acidic constants.

\section{Determination of the Total Surface Site Concentration $\left(H_{S}\right)$}

The total surface site concentration was calculated from the two equivalence points in the Gran plot of the hydroxide titration (see Fig. 2b, $V_{\mathrm{e} 1}$ and $V_{\mathrm{e} 2}$ ) after subtracting the hydroxide consumed by the blank solution, as shown in the 
a

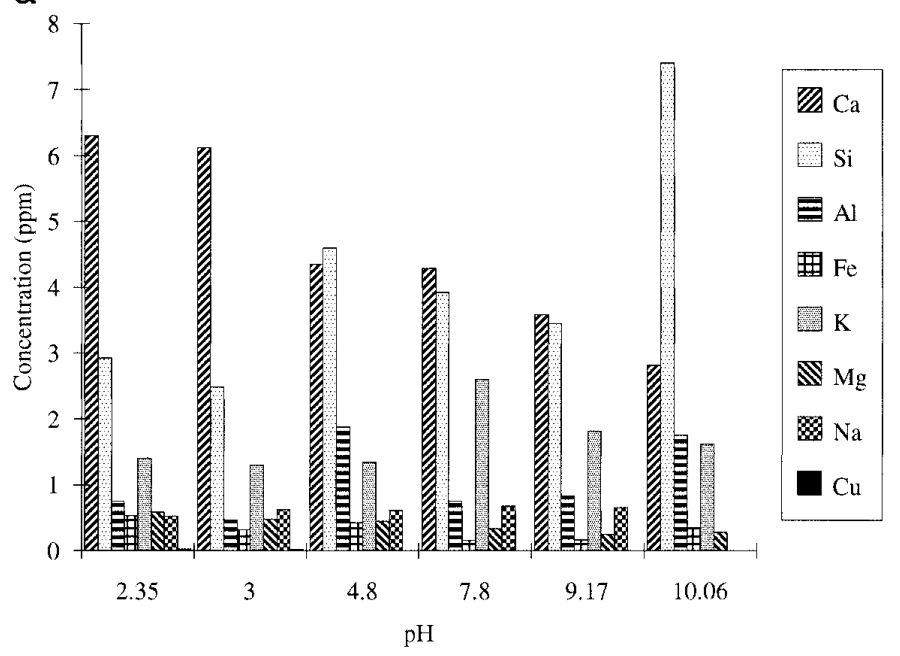

b

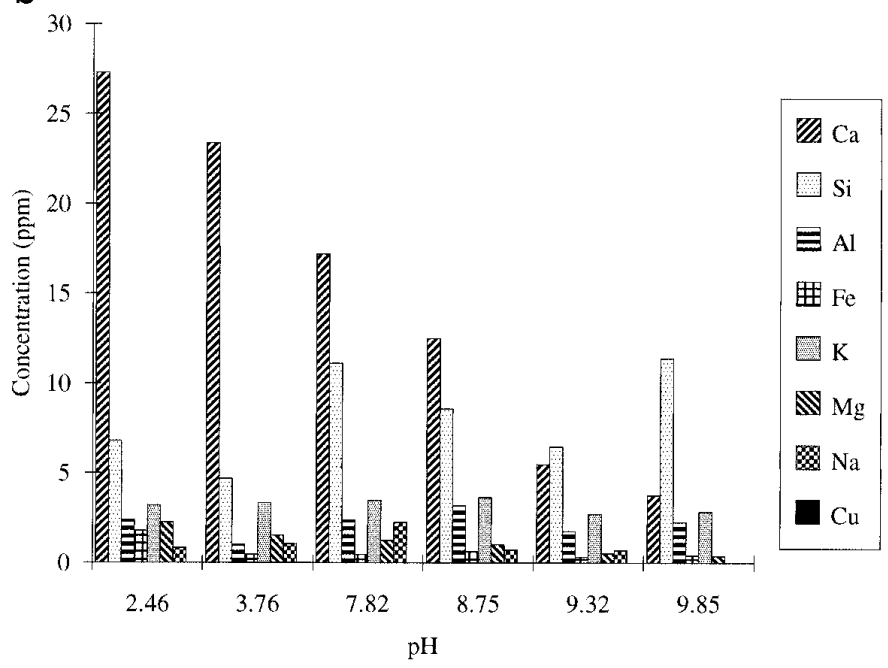

FIG. 3. The solubility of illite suspensions at different $\mathrm{pH}$ values. a. Illite $=1 \mathrm{~g} /$ liter. b. Illite $=5 \mathrm{~g} /$ liter.

equation below. The reason for using this method is discussed in the next section.

$$
\begin{aligned}
H_{\mathrm{S}}=\left[\left(V_{\mathrm{e} 2}-\right.\right. & \left.\left.V_{\mathrm{e} 1}\right) C_{\mathrm{b}}\right)_{\text {sample }} \\
& \left.\left.-\left(V_{\mathrm{e} 2}-V_{\mathrm{e} 1}\right) C_{\mathrm{b}}\right)_{\mathrm{blank}}\right] / V_{0}(\mathrm{~mol} / \text { liter })
\end{aligned}
$$

\section{Calculation of the Average Number of Protons Reacted per Surface Site (Z)}

At each titration point, the average number of protons reacted per surface site $(Z)$ (Fig. 5) was determined by

$$
\begin{aligned}
Z=\left[\text { TOTH }-10^{-\mathrm{pH}}+\right. & \left.10^{-\left(p K_{\mathrm{w}}-\mathrm{pH}\right)}\right] \\
& \times\left(V_{0}+V_{\mathrm{at}}+V_{\mathrm{b}}\right) /\left(H_{\mathrm{S}} V_{0}\right) .
\end{aligned}
$$

TOTH and $\mathrm{H}_{\mathrm{S}}$ were calculated by Eqs. [7] and [8], respectively. For each illite suspension system, the net number of surface reacted protons per surface site, $Z_{\text {net }}(\mathrm{pH}, I)$, was obtained from the difference between the $Z$ values of the sample titration and the corresponding blank titration at the same $\mathrm{pH}$.

$$
Z_{\text {net }}(\mathrm{pH}, I)=Z_{\text {sample }}-Z_{\text {blank }}
$$

\section{RESULTS AND DISCUSSION}

\section{Solubility of the Illite in Pure Water Solutions}

The solubility characteristics of two different illite concentration systems in the $\mathrm{pH}$ range from 2 to 10 (Fig. 3a,

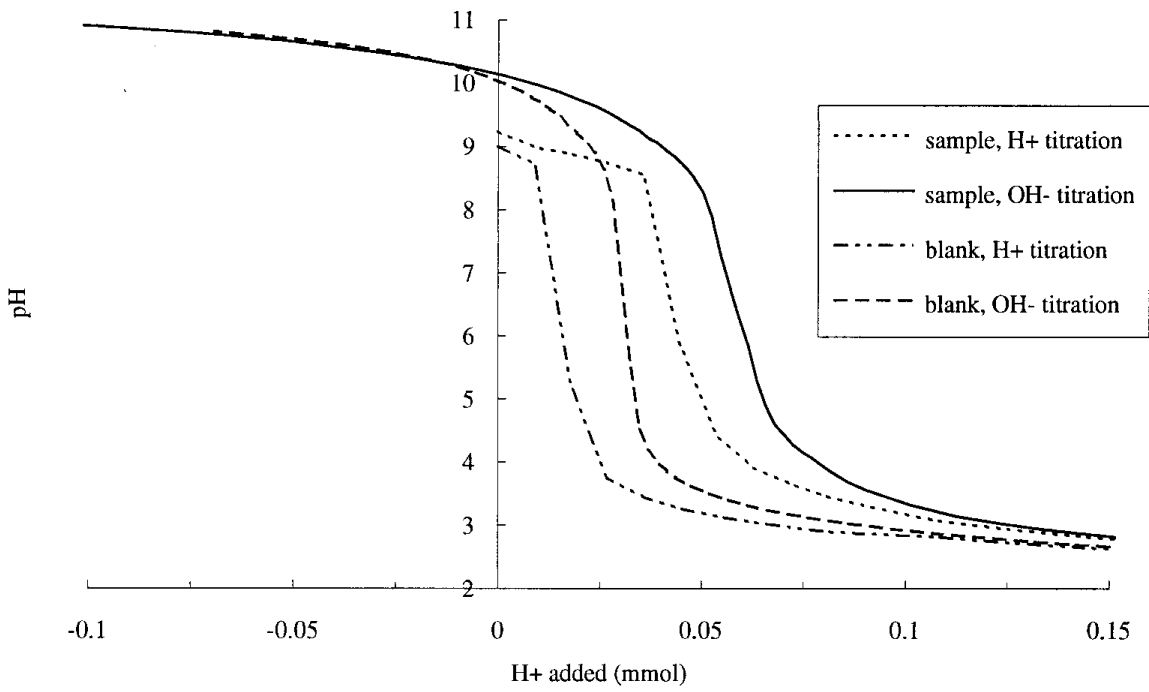

FIG. 4. Potentiometric titrations of an illite suspension and its corresponding supernatant blank system, illite $=5 \mathrm{~g} /$ liter, $I=0.1 M$ NaNO ${ }_{3}$. The titration curves of the illite suspensions with $1 \mathrm{~g}$ /liter illite in $0.1 M \mathrm{NaNO}_{3}$ and $5 \mathrm{~g} /$ liter illite in $0.5 M \mathrm{NaNO}_{3}$, and their corresponding supernatant blanks are similar to the curves in this figure. 


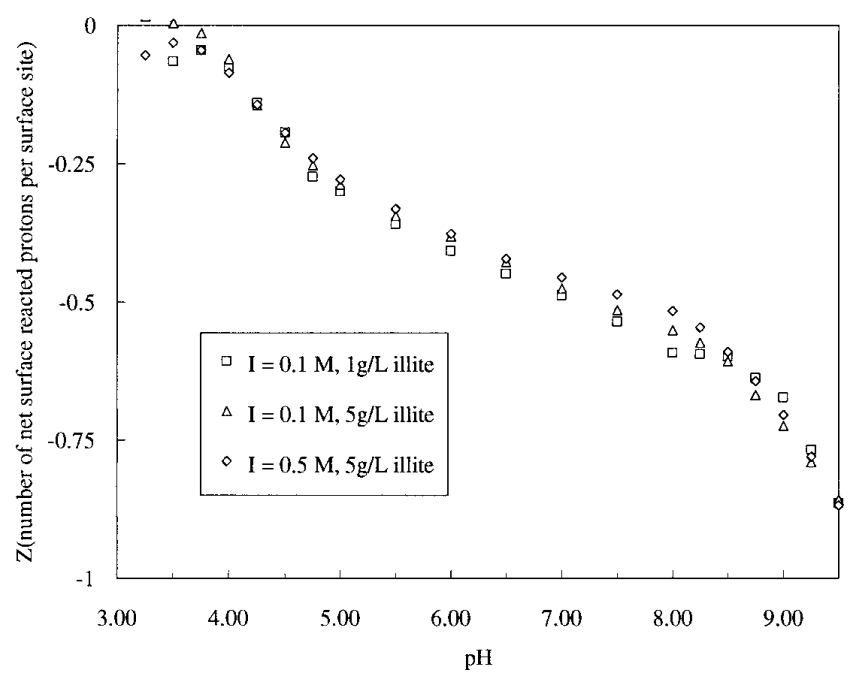

FIG. 5. pH-dependent net number of surface-reacted protons per surface site.

illite $=1 \mathrm{~g} /$ liter and Fig. $3 \mathrm{~b}$, illite $=5 \mathrm{~g} /$ liter $)$ indicate two things. First, for each illite concentration the amount of each element released from the illite, except for $\mathrm{Si}$ and $\mathrm{Ca}$, changes little with $\mathrm{pH}$. The release of $\mathrm{Si}$ increases with the increase of $\mathrm{pH}$, and the release of $\mathrm{Ca}$ increases with the decrease of $\mathrm{pH}$. For the trace element copper, little release from the illite sample was found. Secondly, at similar $\mathrm{pH}$ levels the release of each element other than $\mathrm{Ca}$ is independent of the solid concentration. We can see from Figs. 3a and $3 b$ that a fivefold increase in illite concentration does not lead to a proportional increase in the release of all the studied elements, except for $\mathrm{Ca}$. In the case of $\mathrm{Ca}$, there seems to be a close relationship between its release and the illite concentration.

Even though significant dissolution of clay mineral kaolinite and kaolinitic soils in acidic aqueous solutions has been reported $(19,33)$, we found no notable dissolution of illite at acidic conditions in our study (Fig. 3). This can be explained as a consequence of the difference between the structures of illite and kaolinite. Kaolinite is a 1:1 layer-type clay mineral composed of one gibbsite sheet $\left(\gamma-\mathrm{Al}(\mathrm{OH})_{3}\right)$ and one silica sheet $\left(\mathrm{SiO}_{4}\right)$. Kaolinite-solution systems contain three kinds of surfaces: a gibbsite surface, a siloxane surface, and an edge surface, which is a complex oxide of the two constituents $\mathrm{Al}(\mathrm{OH})_{3}$ and $\mathrm{SiO}_{2}$. Wieland and Stumm demonstrated in their study of the dissolution kinetics of kaolinite that the proton-promoted dissolution of kaolinite is the consequence of the acid-base properties of $\mathrm{OH}$ groups at the edge and gibbsite surfaces of a kaolinite platelet $(19,20)$. In contrast, illite is a 2:1 layer-type clay mineral composed of one gibbsite sheet sandwiched between two silica sheets. Illite-solution systems have only two kinds of surfaces, a siloxane surface and an edge surface. Since gibbsite sheets do not come into direct contact with water in illite suspensions, we conclude that illite should be more stable than kaolinite in aqueous solutions, which explains the lack of significant dissolution of illite at acidic conditions in our experiments.

\section{Carbonate Problem in the Illite}

Carbonates in natural minerals can consume protons during the addition of acid, causing errors in the evaluation of the surface acid-base properties from the results of potentiometric titrations. This carbonate problem can be seen clearly from our titration curves (Fig. 4), which show that for both the sample and the blank titrations the route of the acid titration is very different from that of the hydroxide backtitration. We solved this problem by using a backtitration procedure, first eliminating the carbonates through acid titration and then analyzing the experimental data from the following alkaline titration to evaluate the acidic behaviors of the illite surfaces. (A similar backtitration procedure has been used to evaluate the surface charge characteristics of soils for the purpose of eliminating the influence of the soil dissolution and the hydrolysis of soluble ions on the consumption of $\mathrm{H}^{+}$or $\mathrm{OH}^{-}$by the surface reactions $(34,35)$ ).

On the basis of our titration data, we estimated the amount of protons consumed by the carbonates $\left(\mathrm{H}_{\mathrm{c}}\right)$ in a suspension with $5 \mathrm{~g}$ /liter illite in $0.1 \mathrm{M} \mathrm{NaNO}_{3}$ (the absolute amount of illite in this system is $0.25 \mathrm{~g}$ ). This was done by subtracting the free protons $\left(\mathrm{H}_{\mathrm{f}}\right)$ and the protons consumed by the surfaces $\left(\mathrm{H}_{\mathrm{s}}\right)$ and the supernatant blank $\left(\mathrm{H}_{\mathrm{b}}\right)$ from the total added acid $\left(\mathrm{H}_{\mathrm{at}}\right)$,

$$
\mathrm{H}_{\mathrm{c}}=\mathrm{H}_{\mathrm{at}}-\mathrm{H}_{\mathrm{s}}-\mathrm{H}_{\mathrm{b}}-\mathrm{H}_{\mathrm{f}}
$$

Our calculations show the carbonates in $0.25 \mathrm{~g}$ illite consumed $0.041 \mathrm{mmol}$ of protons, the same amount as consumed by $2.05 \mathrm{mg} \mathrm{CaCO}_{3}$. This result approximates what we obtained from the gas analyzer carbonate analysis, which gave a value of $2.97 \mathrm{mg} \mathrm{CaCO}_{3}$ for the carbonates in 0.25 $\mathrm{g}$ illite.

Furthermore, the existence of carbonates in the illite suspension and their consumption of protons during the acid titration is in agreement with the behavior of $\mathrm{Ca}$ in the solubility experiments (Figs. 3a and 3b). Calcite is a very common compound existing in natural minerals, and its dissolution increases with the decrease of $\mathrm{pH}$, as represented by the equation

$$
\mathrm{CaCO}_{3}+2 \mathrm{H}^{+} \rightarrow \mathrm{Ca}^{2+}+\mathrm{H}_{2} \mathrm{O}+\mathrm{CO}_{2} .
$$

This can explain why the release of $\mathrm{Ca}$ from illite increases with the decrease of $\mathrm{pH}$ and also the close relationship between the release of $\mathrm{Ca}$ and the illite solid concentration (Fig. 3).

Finally, since the common method for evaluating the total surface site concentration $\left(\mathrm{H}_{\mathrm{S}}\right)$ for a solid suspension is to use potentiometric titrations $(11,36)$, this carbonate prob- 
lem also causes errors in the determination of $\mathrm{H}_{S}$. The total surface site concentration is usually calculated from the titration data as

$$
\begin{aligned}
\mathrm{H}_{\mathrm{S}}=\left[\left(V_{\mathrm{at}} C_{\mathrm{a}}\right.\right. & \left.-V_{\mathrm{eb}} C_{\mathrm{b}}\right)_{\text {sample }} \\
& \left.-\left(V_{\mathrm{at}} C_{\mathrm{a}}-V_{\mathrm{eb}} C_{\mathrm{b}}\right)_{\mathrm{blank}}\right] / V_{0},(\mathrm{~mol} / \text { liter })
\end{aligned}
$$

where $V_{\text {at }}$ is the volume of excess acid added in the beginning of the experiment, $V_{\mathrm{eb}}$ is the volume of hydroxide at the equivalence point in the following alkaline titration, and $C_{\mathrm{a}}$ and $C_{\mathrm{b}}$ are the concentrations of the acid and the hydroxide, respectively. Regarding the natural particles with impurity compounds (e.g., carbonates), the value of $\mathrm{H}_{\mathrm{S}}$ determined by Eq. [13] includes the amount of protons consumed not only by the mineral surface but also by the impurity compounds; it therefore overestimates the true surface site concentration. In order to get the "real" total surface concentration of illite, we modified this calculation by using the two $V_{\mathrm{e}}$ values in the Gran plot of the hydroxide titration (as shown in Eq. [8]). Our rationale for doing this was as follows. Since the carbonates in the illite were eliminated during the acid titration, the $\mathrm{OH}^{-}$ions added during the following hydroxide titration react in three main ways: by neutralizing the excess $\mathrm{H}^{+}$(before $V_{\mathrm{e} 1}$ in Fig. 2b), by binding with the $\mathrm{OH}^{-}$acceptors in the suspension (between $V_{\mathrm{e} 1}$ and $\left.V_{\mathrm{e} 2}\right)$, and by contributing excess $\mathrm{OH}^{-}$to the system (after $V_{\mathrm{e} 2}$ ). Therefore, after the amount of $\mathrm{OH}^{-}$consumed by the blank was subtracted, the amount of hydroxide between $V_{\mathrm{e} 1}$ and $V_{\mathrm{e} 2}$ was taken to be the hydroxide related to the illite surface reactions.

\section{Model Descriptions of Acid-Base Reactions in the Illite Suspensions}

(1) Supernatant blank systems. Since illite is basically hydrous aluminum silicate, we assumed that the proton reactions in the supernatants of illite suspensions are those of aluminum and silicon in water solutions. We therefore applied the acidic constants of $\mathrm{Al}^{3+}$ and $\mathrm{Si}(\mathrm{OH})_{4}$ in water solutions (37) to simulate the supernatant titration. A FITEQL program (version 2.0) (23) was used to analyze the experimental data, with the total concentrations of Al (TO$\mathrm{T}(\mathrm{Al})$ ) and $\mathrm{Si}(\mathrm{TOT}(\mathrm{Si}))$ in the supernatant as two adjustable parameters. The optimized TOT ( $\mathrm{Al})$ and TOT $(\mathrm{Si})$ and the corresponding error analysis for each illite system, together with the Al, Si concentrations measured by ICP in the solubility experiments (when no acid or base was added), are summarized in Table 2. As indicated in Table 2 , the TOT $(\mathrm{Al})$ and TOT $(\mathrm{Si})$ calculated from the titration data are comparable to those measured by ICP analysis. They are in the same order of magnitude. (Some errors might be caused by the difference of the ionic strength in the two experiments.) These results support our assumption that the proton reactions in the supernatants of the illite suspensions are those of aluminum and silicon in water solutions. Our assumption is further supported by the good fit of the calculated titration curves to the experimental data from systems with different illite concentrations and ionic strengths (as shown in Fig. 6). The calculated titration curves in Fig. 6 were obtained by using both the optimized TOT(Al) and TOT(Si) for each supernatant and the acidic constants of $\mathrm{Al}\left(\mathrm{H}_{2} \mathrm{O}\right)_{6}^{3+}$ and $\mathrm{Si}(\mathrm{OH})_{4}$ in water solutions to simulate the supernatant blank titration.

(2) Illite suspension systems. The surface acidic constants of different illite suspension systems were derived from the potentiometric titration data within the framework of the constant capacitance model. During the calculation, the acidic constants of $\mathrm{Al}\left(\mathrm{H}_{2} \mathrm{O}\right)_{6}^{3+}$ and $\mathrm{Si}(\mathrm{OH})_{4}$ in water solutions and the total concentrations of $\mathrm{Al}$ and $\mathrm{Si}$ in the supernatant (Table 2) were input into the data file of the FITEQL program to simulate the blank of each illite suspension sample. The calculations were performed using different values of the specific capacitance $(C)$ until the best fit was obtained.

In studies of the surface acid-base behaviors of aqueous kaolinite and montmorillonite $(8,9,19,38)$, a weakly acidic surface functional group ( $\equiv \mathrm{XH})$ accounting for ion exchange reactions was incorporated along with the amphoteric surface hydroxyl group ( $\equiv \mathrm{SOH})$ into the surface protonation model. In our work, since we used very high background electrolyte concentrations ( 0.1 and $\left.0.5 \mathrm{M} \mathrm{NaNO}_{3}\right)$, which were at least 100 times higher than the proton concentrations (about $0.001 M$ at the highest level), and since ion exchange reactions are usually much weaker than chemisorptions, we only considered the acid-base behavior of the amphoteric surface hydroxyl groups ( $\equiv \mathrm{SOH})$ in simulating the surface reactions of illite. Two surface protonation models (the one site-one $\mathrm{p} K_{\mathrm{a}}$ model and the two sites-two $\mathrm{p} K_{\mathrm{a}} \mathrm{s}$ model as defined below) were used for the determination of the surface acidic constants. The best-fitted constants optimized by FITEQL for each surface protonation model and illite suspension, as well as their error analysis and the corresponding specific capacitance (C), are listed with other surface characteristic parameters in Table 3.

One site-one $p K_{a}$ model (Model I). In this model, we assume that the amphoteric surface hydroxyl groups ( $\equiv \mathrm{SOH})$, which are treated as homogeneous, only release protons to form negatively charged surface sites $\left(\equiv \mathrm{SO}^{-}\right)$, as described by Eq. [2],

$$
\equiv \mathrm{SOH} \rightleftarrows \equiv \mathrm{SO}^{-}+\mathrm{H}^{+} . \quad K_{\mathrm{a}}^{\mathrm{int}}
$$

This assumption is based on the following:

(1) The information in the Gran plots of the hydroxide titrations (Fig. 2b) implies that no surface reaction occurs before $V_{\mathrm{e} 1}$, i.e., during the addition of protons.

(2) The net number of surface reacted protons per surface site $Z_{\text {net }}(\mathrm{pH}, I)$ for the three illite suspensions (Fig. 5) shows 
TABLE 2

Total Concentrations of $\mathrm{Al}$ and $\mathrm{Si}$ in the Supernatants of the Corresponding Illite Suspensions $\left(25^{\circ} \mathrm{C}\right)$

\begin{tabular}{|c|c|c|c|c|c|c|c|c|}
\hline \multicolumn{6}{|c|}{ Optimization of the experimental data } & \multicolumn{3}{|c|}{ Results from ICP analysis } \\
\hline Illite suspension & $\begin{array}{c}\text { TOT(Al) } \\
\left(\times 10^{-5} M\right)\end{array}$ & $\begin{array}{c}\sigma_{\mathrm{Al}}^{a} \\
\left(\times 10^{-5} M\right)\end{array}$ & $\begin{array}{c}\text { TOT(Si) } \\
\left(\times 10^{-4} M\right)\end{array}$ & $\begin{array}{c}\sigma_{\mathrm{Si}^{a}}^{a} \\
\left(\times 10^{-4} M\right)\end{array}$ & $V_{Y}^{b}$ & Illite suspension & $\begin{array}{c}\mathrm{TOT}(\mathrm{Al}) \\
\left(\times 10^{-5} M\right)\end{array}$ & $\begin{array}{c}\mathrm{TOT}(\mathrm{Si}) \\
\left(\times 10^{-4} M\right)\end{array}$ \\
\hline Illite $=1 \mathrm{~g} /$ liter, $I=0.1 M$ & 2.34 & 0.061 & 2.92 & 0.043 & 6.92 & Illite $=1 \mathrm{~g} /$ liter, $I=0$ & 3.07 & 1.23 \\
\hline Illite $=5 \mathrm{~g} /$ liter, $I=0.1 \mathrm{M}$ & 2.46 & 0.054 & 5.23 & 0.046 & 16.62 & Illite $=5 \mathrm{~g} /$ liter, $I=0$ & 6.48 & 2.30 \\
\hline Illite $=5 \mathrm{~g} /$ liter, $I=0.5 \mathrm{M}$ & 2.20 & 0.054 & 5.59 & 0.043 & 10.72 & & & \\
\hline
\end{tabular}

Acidic constants of $\mathrm{Al}\left(\mathrm{H}_{2} \mathrm{O}\right)_{6}^{3+}$ and $\mathrm{Si}(\mathrm{OH})_{4}$ in water solutions (37)

$$
\begin{aligned}
& \mathrm{Al}\left(\mathrm{H}_{2} \mathrm{O}\right)_{6}^{3+}+\mathrm{OH}^{-} \rightleftarrows \mathrm{Al}\left(\mathrm{H}_{2} \mathrm{O}\right)_{6} \mathrm{OH}^{2+} \\
& \mathrm{Al}\left(\mathrm{H}_{2} \mathrm{O}\right)_{6}^{3+}+2 \mathrm{OH}^{-} \rightleftarrows \mathrm{Al}\left(\mathrm{H}_{2} \mathrm{O}\right)_{6}(\mathrm{OH})_{2}^{+} \\
& \mathrm{Si}(\mathrm{OH})_{4} \rightleftarrows \mathrm{SiO}(\mathrm{OH})_{3}^{-}+\mathrm{H}^{+} \\
& \mathrm{SiO}(\mathrm{OH})_{3}^{-} \rightleftarrows \mathrm{SiO}_{2}(\mathrm{OH})_{2}^{2-}+\mathrm{H}^{+}
\end{aligned}
$$

$$
\begin{aligned}
& \log K=8.48\left(25^{\circ} \mathrm{C}, I=0.1\right) \\
& \log K=17.6\left(25^{\circ} \mathrm{C}, I=0.1\right) \\
& \log K=-9.46\left(25^{\circ} \mathrm{C}, I=0.5\right) \\
& \log K=-12.56\left(25^{\circ} \mathrm{C}, I=0.5\right)
\end{aligned}
$$

\footnotetext{
${ }^{a} \sigma_{\mathrm{Al}}$ and $\sigma_{\mathrm{Si}}$ are the standard deviations of the TOT(Al) and TOT(Si), respectively.

${ }^{b} V_{Y}$ is the main indicator of fitness in FITEQL program. Values of $V_{Y}$ between 0.1 and 20 are typical for a good fit (23).
}

that within the entire studied $\mathrm{pH}$ range $(\mathrm{pH} 3-10)$, only deprotonation reaction occurs at the illite surface.

(3) The zeta potential measurements (Fig. 7) indicate that the illite surface is still negatively charged even at very low $\mathrm{pH}$ values $(\mathrm{pH} \mathrm{2-3)}$.

Two sites-two $p K_{a}$ s model (Model II). This model is a modification of Model I suggested by an analysis of Fig. 5. In Fig. 5, the Z-plots for the three illite suspensions reach a plateau when $Z_{\text {net }}(\mathrm{pH}, I)$ is approximately -0.5 , which corresponds to a situation in which half of the total surface sites have released their protons. This leads us to assume

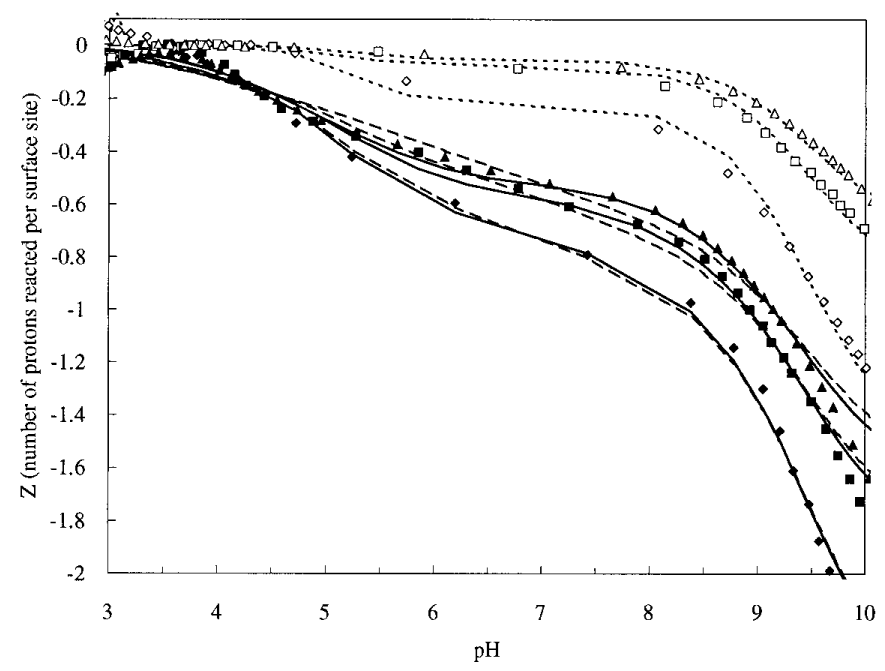

FIG. 6. Model descriptions of the potentiometric titrations of different illite suspensions and the corresponding experimental data. Open points: experimental data of the blank titrations. Solid points: experimental data of the sample titrations. Diamond: Illite $=1 \mathrm{~g} /$ liter, $I=0.1 \mathrm{M}$. Square: illite $=5 \mathrm{~g} /$ liter, $I=0.1 \mathrm{M}$. Triangle: illite $=5 \mathrm{~g} /$ liter, $I=0.5 \mathrm{M}$. Dotted lines: simulations of the blank titrations using $\mathrm{Si}(\mathrm{OH})_{4}$ and $\mathrm{Al}\left(\mathrm{H}_{2} \mathrm{O}\right)^{3+}$ proton reactions in water solutions. Dashed lines: Model I descriptions of the sample titrations. Solid lines: Model II descriptions of the sample titrations. that (1) the illite surface is heterogeneous, (2) there are mainly two kinds of surface sites with different hydroxide affinities at the illite/water interface, and (3) the concentration ratio of these two kinds of surface sites is $1: 1$. Therefore, the reactions of the amphoteric surface hydroxyl groups are expressed as:

$$
\equiv \mathrm{S}_{\mathrm{I}} \mathrm{OH} \rightleftarrows \equiv \mathrm{S}_{\mathrm{I}} \mathrm{O}^{-}+\mathrm{H}^{+}, \quad K_{\mathrm{a}_{\mathrm{I}}}^{\mathrm{int}}
$$

and

$$
\equiv \mathrm{S}_{\mathrm{II}} \mathrm{OH} \rightleftarrows \equiv \mathrm{S}_{\mathrm{II}} \mathrm{O}^{-}+\mathrm{H}^{+} . \quad K_{\mathrm{a}_{\mathrm{II}}}^{\mathrm{int}}
$$

In this work, we conducted experiments on systems with two illite concentrations ( 1 and $5 \mathrm{~g} /$ liter) of different ionic strengths. Fig. 6 shows that both Model I and Model II fit very well with all the experimental data of the studied systems. Since both models consider only deprotonation reactions at the illite aqueous surfaces, they suggest that the surface behavior of the illite is similar to that of amorphous $\mathrm{SiO}_{2}$, which can also be represented by only one deprotonation reaction in silica/water systems (39). This is unsurprising since silicate is the dominant component in illite.

Model I and Model II differ from each other in one major respect. Model I treats the illite surface as homogeneous while Model II assumes that there are two kinds of surface sites with different hydroxide affinities at the illite/water interface. Comparing the $\mathrm{p} K_{\mathrm{a}}^{\mathrm{int}}$ values obtained from these two models (Table 3 ), we can see that the $\mathrm{p} K_{\mathrm{a}}^{\mathrm{int}}$ value in Model I (which is between 4.12 and 4.23) is similar to the $\mathrm{p} K_{\mathrm{a}_{\mathrm{I}}}^{\mathrm{int}}$ value for the stronger surface sites in Model II (which is between 4.17 and 4.44). This implies that Model I can be regarded as a simplification of Model II. In other words, Model I simplifies the heterogeneous illite surface as a system with uniform acid-base properties and simulates the surface acid-base characteristics with the behavior of the 
TABLE 3

Surface Parameters of Different Illite Suspension Systems $\left(25^{\circ} \mathrm{C}\right)$

\begin{tabular}{|c|c|c|c|c|c|c|c|}
\hline \multicolumn{8}{|c|}{ Illite $=1 \mathrm{~g} /$ liter, $I=0.1, M \mathrm{NaNO}_{3}, D_{\mathrm{S}}{ }^{b}=5.9$ sites $\mathrm{nm}^{-2}$} \\
\hline & $H_{\mathrm{S}}\left(\times 10^{-3} M\right)$ & $C\left(\mathrm{Fm}^{-2}\right)$ & $\mathrm{p} K_{\mathrm{a}_{1}}^{\mathrm{int}}$ & $\sigma_{\mathrm{pK}_{\mathrm{a}_{1}}^{\mathrm{int}}}$ & $\mathrm{p} K_{\mathrm{a}_{\mathrm{II}}}^{\text {int }}$ & $\sigma_{\mathrm{p} K_{\mathrm{au}_{\mathrm{H}}}^{\text {int }}}$ & $V_{Y}$ \\
\hline Model I & 0.220 & 3.0 & 4.18 & 0.028 & & & 11.27 \\
\hline Model II & $H_{\mathrm{S}_{\mathrm{I}}}{ }^{a}=0.110$ & 5.0 & 4.17 & 0.020 & & & 10.03 \\
\hline & $H_{\mathrm{S}_{\mathrm{II}}}{ }^{a}=0.110$ & & & & 6.35 & 0.052 & \\
\hline \multicolumn{8}{|c|}{ 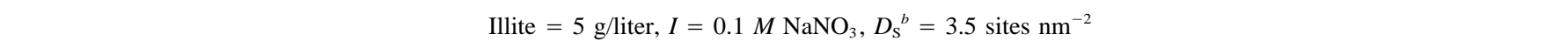 } \\
\hline & $H_{\mathrm{S}}\left(\times 10^{-3} M\right)$ & $C\left(\mathrm{Fm}^{-2}\right)$ & $\mathrm{p} K_{\mathrm{a}_{1}}^{\mathrm{int}}$ & $\sigma_{\mathrm{P}_{\mathrm{a}_{1}}^{\mathrm{int}}}$ & $\mathrm{p} K_{\mathrm{a}_{\mathrm{II}}}^{\mathrm{int}}$ & $\sigma_{\mathrm{p} K_{\mathrm{p}_{\mathrm{a}}}^{\text {int }}}$ & $V_{Y}$ \\
\hline Model I & 0.642 & 1.7 & 4.23 & 0.011 & & & 34.05 \\
\hline Model II & $H_{\mathrm{S}_{\mathrm{I}}}^{a}=0.321$ & 4.1 & 4.38 & 0.011 & & & 25.42 \\
\hline & $H_{\mathrm{S}_{\mathrm{II}}}{ }^{a}=0.321$ & & & & 7.23 & 0.022 & \\
\hline \multicolumn{8}{|c|}{ Illite $=5 \mathrm{~g} /$ liter, $I=0.5 M \mathrm{NaNO}_{3}, D_{\mathrm{s}}{ }^{b}=4.7$ sites nm${ }^{-2}$} \\
\hline & $H_{\mathrm{S}}\left(\times 10^{-3} \mathrm{M}\right)$ & $C\left(\mathrm{Fm}^{-2}\right)$ & $\mathrm{p} K_{\mathrm{a}_{1}}^{\mathrm{int}}$ & $\sigma_{\mathrm{pK}_{\mathrm{a}_{1}}^{\mathrm{int}}}^{\mathrm{int}}$ & $\mathrm{p} K_{\mathrm{a}_{\mathrm{II}}}^{\mathrm{int}}$ & $\sigma_{\mathrm{p} K_{\mathrm{an}_{\mathrm{H}}}^{\mathrm{int}}}$ & $V_{Y}$ \\
\hline Model I & 0.878 & 2.2 & 4.12 & 0.009 & & & 35.49 \\
\hline \multirow{2}{*}{ Model II } & $H_{\mathrm{S}_{1}}^{a}=0.439$ & 7.4 & 4.44 & 0.088 & & & 13.39 \\
\hline & $H_{\mathrm{S}_{\mathrm{II}}}{ }^{a}=0.439$ & & & & 7.74 & 0.017 & \\
\hline
\end{tabular}

${ }^{a} H_{\mathrm{S}_{\mathrm{I}}}+H_{\mathrm{S}_{\mathrm{II}}}=H_{\mathrm{S}}, H_{\mathrm{S}_{\mathrm{I}}}: H_{\mathrm{S}_{\mathrm{II}}}=1: 1$

${ }^{b} D_{\mathrm{S}}$ is the surface site density calculated from $H_{\mathrm{S}}(M)$ using equation $D_{\mathrm{S}}=\left(H_{\mathrm{S}} \times N_{\mathrm{A}}\right) /\left(S \times C_{\mathrm{S}} \times 10^{18}\right)\left(\right.$ sites $\left.\mathrm{nm}^{-2}\right)$, where $N_{\mathrm{A}}$ is the Avogadro's number $\left(6.022 \times 10^{23} \mathrm{~mol}^{-1}\right), S$ the $N_{2} /$ BET surface area $\left(22.3 \mathrm{~m}^{2} \mathrm{~g}^{-1}\right)$, and $C_{\mathrm{s}}$ the illite solid concentration $\left(\mathrm{g} / \mathrm{liter}^{-1}\right)$.

stronger surface sites. Since Model II considers the heterogeneity of the illite surface, it gives more detailed descriptions of the acid-base behaviors of the aqueous illite surfaces than Model I. However, Model I has the advantage of simplicity. It needs only two adjustable parameters $\left(\mathrm{p} K_{\mathrm{a}}^{\mathrm{int}}\right.$ and $C$ ) to give reasonable descriptions of the surface properties of the illite-solution systems.

Besides Model I and Model II, we also tested two other surface protonation models, a one site-two $\mathrm{p} K_{\mathrm{a}} \mathrm{s}$ model and a two site-three $\mathrm{p} K_{\mathrm{a}} \mathrm{s}$ model, to explain the behavior of the surface hydroxyl groups.

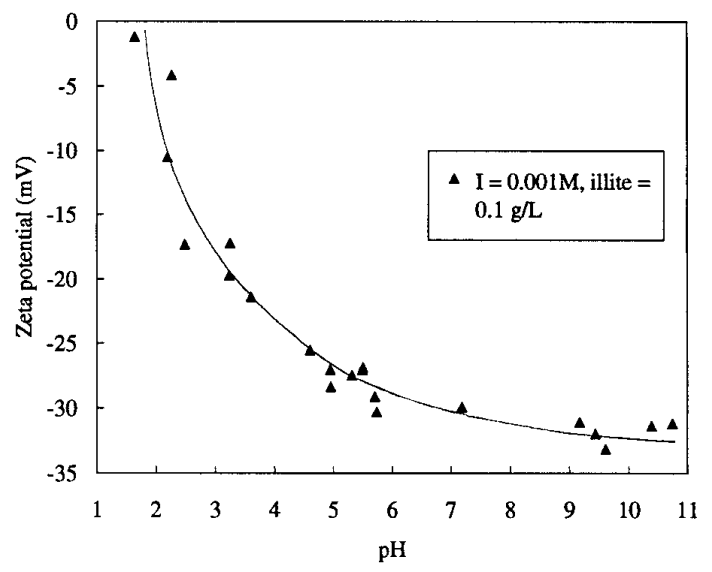

FIG. 7. $\mathrm{pH}$-dependent zeta potential of an illite/water suspension, illite $=0.1 \mathrm{~g} /$ liter, $I=0.001 M \mathrm{NaNO}_{3}$.
One site-two $p K_{a} s$ model. This surface protonation model is typically used in surface complexation models to study the surface acidic behaviors of solid/water systems $(11,19,21)$. It assumes that the illite surface is homogeneous, and that two acidic reactions, one protonation and one deprotonation (as shown in Eqs. [1] and [2]), occur at the amphoteric surface hydroxyl groups $(\equiv \mathrm{SOH})$. By using this model, we got two surface acidic constants at rather low $\mathrm{pH}$ values $\left(\mathrm{p} K_{\mathrm{a} 1}^{\mathrm{int}}=2.27-2.83, \mathrm{p} K_{\mathrm{a} 2}^{\mathrm{int}}=3.40-4.01\right)$ for each illite suspension system, which suggests that there should be surface protonation-deprotonation reactions even at a $\mathrm{pH}$ range as low as $2-3.5$. This is inconsistent with the experimental results shown in the Gran plots (Fig. 2), which indicate that there are no surface reactions in the $\mathrm{pH}$ range $2-3.5$. In addition, the two obtained $\mathrm{p} K_{\mathrm{a}}^{\mathrm{int}}$ values for this model are in a very narrow range (with a difference less than two $\mathrm{pH}$ units), which implies that once surface protonation occurs, surface deprotonation immediately begins to counterbalance the formed positive surface sites by forming negative surface sites. Given the above considerations, it seems more reasonable not to include surface protonation reactions to describe the acid-base behaviors of the aqueous illite surfaces. We therefore conclude that this model is not suitable for the illite/water systems we examined.

It should be mentioned that Motta and Miranda (21) also employed this surface protonation model to study the surface behavior of illite under the assumption of the constant capacitance model, but they got two acid-base constants in the 
neutral and alkaline $\mathrm{pH}$ regions $\left(\mathrm{p} K_{\mathrm{a} 1}^{\mathrm{int}}=7.5, \mathrm{p} K_{\mathrm{a} 2}^{\mathrm{int}}=11.7\right)$. These results are significantly different from ours. This discrepancy might be due to the differences in the sources of the sample and/or in the experimental method, but details of the illite composition analysis and the experimental procedures given in their paper are insufficient to determine whether this is in fact the case.

Two sites-three $p K_{a} s$ model. This model considers the illite surface as heterogeneous. Since the ratio of the amounts of the two oxides in illite $\left(\mathrm{SiO}_{2}: \gamma-\mathrm{Al}(\mathrm{OH})_{3}\right)$ is $2: 1$, we assume that there are two kinds of surface sites $\left(\equiv \mathrm{S}_{\mathrm{I}} \mathrm{OH}\right.$ and $\equiv \mathrm{S}_{\mathrm{II}} \mathrm{OH}$ ) and that their concentration ratio is $2: 1$. We also assume that $\equiv \mathrm{S}_{\mathrm{I}} \mathrm{OH}$ sites only have deprotonation reaction (as described by Eq. [2]), behavior which is similar to that of pure $\mathrm{SiO}_{2}$ in water solutions, and that $\equiv \mathrm{S}_{\mathrm{II}} \mathrm{OH}$ sites have both protonation and deprotonation reactions (as described by Eqs. [1] and [2], respectively), a situation which is similar to the surface acidic behavior of pure $\gamma-\mathrm{Al}(\mathrm{OH})_{3}$ in water solutions. Under these assumptions, we obtained three $\mathrm{p} K_{\mathrm{a}}^{\text {int }}$ values from the model calculation. For $\equiv \mathrm{S}_{\mathrm{I}} \mathrm{OH}$, the $\mathrm{p} K_{\mathrm{a}}^{\mathrm{int}}$ is in the range 3.46-3.68; for $\equiv \mathrm{S}_{\mathrm{II}} \mathrm{OH}$, the two $\mathrm{p} K_{\mathrm{a}}^{\mathrm{int}} \mathrm{s}$ are in ranges 6.00-6.19 and 7.32-7.66.

This model behaves no better than Models I and II in fitting the experimental data, but it needs more model-relevant parameters. In addition, the model assumption (namely that the concentration ratio of the two kinds of surface sites is 2:1) is based only on structure analysis, not on solid experimental evidence. Furthermore, the model predicts that there should be protonation reactions $\left(\equiv \mathrm{S}_{\mathrm{II}} \mathrm{OH}+\mathrm{H}^{+} \rightleftarrows\right.$ $\equiv \mathrm{S}_{\mathrm{II}} \mathrm{OH}_{2}^{+}$) in the illite/water systems, which is countered by the fact that we detected only deprotonation reactions within the entire studied $\mathrm{pH}$ range ( $\mathrm{pH} \mathrm{3-10)} \mathrm{(Fig.} \mathrm{5).}$ Finally, when using this surface protonation model, we found during the calculation that the model gave surface acidic constants that were related to randomly chosen initial constants input into the FITEQL programs. Therefore, we conclude that this model is also not suitable for the illite/water suspensions.

\section{CONCLUSIONS}

In this work, we studied the surface characteristics of illite/water suspensions. From the experimental results and the analysis above, we arrive at the following conclusions.

(1) Unlike clay mineral kaolinite, there is no significant dissolution of illite in acidic aqueous solutions.

(2) The interference of carbonates is a big problem in the study of surface acid-base properties of natural minerals by potentiometric titrations. We suggested that a solution to this problem is to carry a backtitration procedure and to analyze the hydroxide backtitration data to evaluate the surface behaviors.

(3) The proton reactions in the supernatants of illite suspensions can be successfully represented by the proton reactions of $\mathrm{Al}\left(\mathrm{H}_{2} \mathrm{O}\right)^{3+}$ and $\mathrm{Si}(\mathrm{OH})_{4}$ in water solutions.
(4) Four kinds of surface protonation models are tested to determine the surface acidic constants, two of which were eliminated due to unsuitability. The other two models, the one site-one $\mathrm{p} K_{\mathrm{a}}$ model (Model I) and the two sites-two $\mathrm{p} K_{\mathrm{a}} \mathrm{s}$ model (Model II), were used to illustrate the surface acidic characteristics of the illite suspensions. For the studied illite suspension systems, the $\mathrm{p} K_{\mathrm{a}}^{\mathrm{int}}$ value obtained from the calculation of Model $\mathrm{I}$ is in the range 4.12-4.23; the two $\mathrm{p} K_{\mathrm{a}}^{\mathrm{int}}$ values determined by Model II are in the range 4.174.44 for the stronger surface sites and in the range 6.357.44 for the weaker sites, respectively.

(5) Within the framework of the constant capacitance surface complexation model, both Model I and Model II can give good descriptions of the experimental data of systems with different illite concentrations and ionic strengths. Model I can be considered as a simplification of Model II. Model II has the advantage of considering the heterogeneity of the illite surface; it therefore gives more detailed descriptions of the acid-base behaviors of the aqueous illite surfaces than Model I. Model I has the advantage of simplicity. It needs only two adjustable parameters ( $\mathrm{p} K_{\mathrm{a}}^{\text {int }}$ and $C$ ) to give reasonable descriptions of the surface properties.

\section{ACKN OWLEDGMENTS}

We thank Professor Chen Kaihui of the Geology Institute, Academia Sinica, for providing us with illite samples. We also thank Dr. Lars Gunneriusson of the Division of Inorganic Chemistry, Luleå University of Technology, for his valuable comments and suggestions on earlier drafts of this paper. We express our appreciation to Mr. Jonas Hedlund and Ms. Maine Ranheimer, both of the Department of Chemical and Metallurgical Engineering at Luleå University, for help with the scanning electron microscope measurements and with the gas analyzer measurements, respectively, and to Mr. Wang Qing-guang and Ms. Lin Guozhen, both of the Research Center for Eco-Environmental Sciences, Academia Sinica, for providing $\mathrm{X}$-ray fluorescence spectrograph analysis and X-ray diffraction analysis of the illite sample. Finally, Ms. Du expresses thanks to Luleå University of Technology for providing research funds for this project.

\section{REFERENCES}

1. Anderson, S. J., and Sposito, G., Soil Sci. Soc. Am. J. 56, 1437 (1992).

2. Chorover, J., and Sposito, G., Geochim. Cosmochim. Acta 59, 875 (1995).

3. Mouvet, C., Bourg, A. C. M., Wat. Res. 17, 641 (1983).

4. Charlet, L. "Adsorption of some macronutrient ions on an oxisol. An application of the triple layer model." Ph.D. Thesis, University of California, 1986.

5. Fu, G., and Allen, H. E., Wat. Res. 26, 225 (1992).

6. Du, Q., Wen, X., and Tang, H., China Environ. Sci. 5(2), 140 (1994).

7. Wen, X., Du, Q., and Tang, H., Environ. Sci., to be published (1997).

8. Schindler, P. W., Liechti, P., and Westall, J. C., Neth. J. Agric. Sci. 35, 219 (1987)

9. Stadler, M., and Schindler, P. W., Clays Clay Min. 41, 556 (1993).

10. Schindler, P. W., and Gamsjäger, H., Kolloid Z. Z. Polym. 250, 759 (1972).

11. Hohl, H., and Stumm, W., J. Colloid Interface Sci. 55, 281 (1976).

12. Kummert, R., and Stumm, W., J. Colloid Interface Sci. 75, 373 (1980).

13. Sigg, L. M., "Die Wechselwirkung von Anionen und schwachen 
Săuren mit $\alpha$-FeOOH (Goethit) in wässriger Lösung.', Ph.D. Thesis, Swiss Federal Institute of Technology, Zurich, 1979.

14. Lövgren, L., Sjöberg, S., and Schindler, P. W., Geochim. Cosmochim. Acta 54, 1301 (1990).

15. Sun, Z. X., Forsling, W., Rönngren, L., and Sjöberg, S., Int. J. Min. Proc. 33, 83 (1991).

16. Sun, Z. X., Forsling, W., Rönngren, L., Sjöberg, S., and Schindler, P. W., Colloids Surf. 59, 243 (1991).

17. Rönngren, L., Sjöberg, S., Sun, Z. X., and Forsling, W., in "Flotation science and engineering", (K. A. Matis Ed.), p. 179. Marcel Dekker, Inc., 1995.

18. Wieland, E., "'Die Verwitterung schwerlöslicher Mineralier-ein koordinationschemischer Ansatz zur Beschreibung der Auflösungskinetik." Ph.D. Thesis, ETH Zurich, Switzerland, 1988.

19. Wieland, E., and Stumm, W., Geochim. Cosmochim. Acta 56, 3339 (1992).

20. Stumm, W., "Chemistry of the solid-water interface. Processes at the mineral-water and particle-water interface in natural systems," Chapters 3 and 5. Wiley, New York, 1992.

21. Motta, M. M., and Miranda, C. F., Soil Sci. Soc. Am. J. 53, 380 (1989).

22. Weaver, C. E., and Pollard, L. 'Developments in sedimentology 15. The chemistry of clay minerals.', Elsevier Scientific Publishing Company, New York, 1975.

23. Westall, J. C., "'FITEQL: a program for the determination of chemical equilibrium constants from experimental data.' Rep. 82-01. Department of Chemistry, Oregon State University, Corvallis, OR, 1982.

24. Schindler, P. W., Fürst, B., Dick, R., and Wolf, P. U., J. Colloid Interface Sci. 55, 469 (1976).
25. Stumm, W., Kummert, R., and Sigg, L., Croat. Chem. Acta 53, 291 (1980).

26. Hayes, K. F., "Equilibrium, spectroscopic, and kinetic studies of ion adsorption at the oxide/aqueous interface." Ph.D. Thesis, Stanford University, Stanford, CA, 1987.

27. Davis, J. A., and Kent, D. B., in "Reviews in mineralogy. Volume 23. Mineral-water interface geochemistry', (M. F. Hochella, Jr., and A. F. White Eds.), p. 177. Mineralogical Society of America, 1990.

28. Davis, J. A., James, R. O., and Leckie, J. O., J. Colloid Interface Sci. 63, 480 (1978).

29. Ginstrup, O., Chem. Instrum. 4, 141 (1973).

30. Forsling, W., Hietanen, S., and Sillen, L. G., Acta Chem. Scand. 6, 901 (1952).

31. Gran, G., Analyst 77, 661 (1952).

32. Ludwig, C., and Schindler, P. W., J. Colloid Interface Sci. 169, 284 (1995).

33. Chorover, J., and Sposito, G., Geochim. Cosmochim. Acta 59, 3109 (1995).

34. Duquette, M., and Hendershot, W. H., Soil Sci. Soc. Am. J. 57, 1222 (1993).

35. Duquette, M., and Hendershot, W. H., Soil Sci. Soc. Am. J. 57, 1228 (1993).

36. Sigg, L., and Stumm, W., Colloids Surf. 2, 101 (1981).

37. Smith, R. M., and Martell, A. E., "Critical stability constants. Volume 4: Inorganic complexes.'’ Plenum Press, New York, 1976.

38. Wanner, H., Albinsson, Y., Karnland, O., Wieland, E., Wersin, P., and Charlet, L., Radiochim. Acta 66/67, 157 (1994).

39. Schindler, P. W., and Stumm, W., in "Aquatic surface chemistry" (W. Stumm Ed.), p. 83. Wiley, New York, 1987. 